Gazi University
Journal of Science
PART C: DESIGN AND TECHNOLOGY
http://dergipark.gov.tr/gujsc

\title{
Biologically Inspired Design: A Case Study on Furniture Design Experiences of Interior Architecture Students
}

\author{
Gülçin Cankız ELİBOL ${ }^{1}$ (D) Vildan DÜNDAR TÜRKKAN ${ }^{1, *}$ (D) İsmail BEZCI' ${ }^{1}$ (D) \\ ${ }^{1}$ Hacettepe University of Faculty of Fine Arts, Department of Interior Architecture and Environmental Design, Çankaya/ ANKARA
}

\section{Article Info \\ Research article \\ Received: 05.10 .2021 \\ Revision:12.11.2021 \\ Accepted: 15.11.2021}

\section{Keywords}

\section{Biomimicry}

Design

Furniture

Inspiration

Nature

\begin{abstract}
This study represents the furniture design course outputs of a group of Interior Architecture and Environmental Design Bachelor's Degree students, working on biologically inspired designs. The aim of the study is to put forward an alternative inspiration-transformation-design process by briefly touching the notion of biomimicry; and by this means to raise the awareness of biological inspiration sources in furniture design. Study reveals the conceptual and final product design suggestions of 38 senior class students. Two essential processes were followed in the study; solution-driven design process and problem-driven design process. Findings showed that there have been some common features and differences between these two processes, in terms of finding the starting point and approaching the final design decisions. In both processes, it was seen that the last steps -principle application- involved a particular process, compared to the other steps in each process. Research and analysis based actions, seen in initial steps, gave place to sketching, design development and the usage of professional notions in the final steps. It can also be said that in both processes, the first steps involved the preparation stages regarding the design inputs, whereas in final steps a transform of information regarding the design output can be observed. These two linear processes were thought to be connected with two essential methods; inductive method and deductive method. Within this scope, 38 design ideas were put forward and suggestions were made regarding the processes.
\end{abstract}

\section{INTRODUCTION}

Notion of biomimicry, which constitutes the main focus of this study, was approached and defined in many studies in several disciplines. Maglic (2012) basically specifies that the question is, can we take the philosophy behind the living organisms and use them in the development of mankind? Accordingly, he gives the answer as yes, we can, and it is called Biomimicry [1].

Yet, Biomimicry does not usually mean the direct transfer of an observation in nature to the development of a product, but rather the creative implementation of biological concepts into products [2]. Actually, the practice of borrowing ideas from other domains for solving technical challenges corresponds to a close act; design by analogy. It is a technique widely applied by innovators or designers. Analogous solutions are sourced from other industries, but designers by analogy look to a more distant domain for solutions biology [3].

While designers have used biology as an inspiration for thousands of years, no normative process was existing specific to the practice of biologically inspired design for years [4]. While, in the last few decades, some extensive studies (for instance Helms et al. (2009)) have been conducted on the methodology of this approach in design. Researches on developing biomimetic systems, involving a detailed understanding of biological phenomena with the goal of developing technologies that mimic such phenomena, has steadily been increasing. Notable attempts such as the development of bulletproof jackets by mimicking spider webs; robots that mimic various forms of natural movement such as those by fishes, leeches, and earthworms; and materials that mimic various properties of natural materials are just a few examples of such works [5]. Utilizing trees, flowers, leaves and human skeleton system in roof structures, animal bodies and movement mechanisms in transportation vehicles are such additional examples. Vipers were also 
known to inspire defense industry, as their nervous system was utilized in rocket detectors [6]. Likewise, when robots used in space researches are investigated, it can be seen that many nature inspired studies do exist. Nature inspired robotics technology has been developing by exploring the mechanisms of living organisms. The movement mechanisms of living organisms, their balance, their attitude and the communication between them have been investigated by engineers and researchers from the fields of social sciences, since decades [7].

Design by analogy to biology, often called biomimicry, can simply be defined as the innovation gained through the emulation of biological forms, processes, patterns, and systems [3]. The core concept and the starting point of Biomimicry is that nature develops highly effective, sustainable ways of performing functions, which could benefit designers when tackling comparable challenges [8]. The field of biomimicry, where flora, fauna or entire ecosystems are considered as a basis for design, has attracted worldwide interest in the fields of architecture and engineering. The widespread and practical application of biomimicry as a design method remains, however, largely unrealized; interior architecture commonly use biology as a library of shapes or decoration, but imitating or being inspired solely by natural-looking forms, textures and colors is not biomimetic; it has to involve some biology. Thus, to be truly biomimetic, a design should, in some way, get inspired by the nature's science, not just by the appearances. Nature is a good teacher in this regard, but as it is mentioned above, imitating or being inspired by natural-looking forms, textures and colors alone is not biomimetic [9].

According to Benyus, the quest of biomimicry is to explore nature's masterpieces such as photosynthesis, self-assembly, natural selection, self-sustaining ecosystems, eyes and ears and skin and shells, talking neurons, natural medicines, and more; and then copying these systems and manufacturing processes to solve our own problems; in other words, the conscious emulation of life's genius [10].

Many of the simple structured inventions, facilitating our lives, observed to be nature inspired. Simple and practical solutions actually play essential roles in our lives and observation is the significant way to explore them. Designing activity is generally accepted to be an action based on a problem solving process. Thus, the problem should clearly be defined before this complicated task. Nature is needed to be observed while working on this solutions, and how it strives with it, remains as another question. This route, shall lead a nature friendly design process [6].

Many sustainable approaches have developed for over decades and these approaches found to be generally promoted human well-being by encouraging an efficient use of resources and energy, and by reducing waste or developing techniques for recycling. The approaches used various terminologies that include green design, environmental design, eco-design, sustainable design, bio-climatic design, climate sensitive design, low-energy design etc., all based on environmental principles, striving for efficiencies [11]. The transformation of the notion of Biomimicry into a term indicates to the systematization process regarding the designing activities inspired by nature. As Biomimicry has gained a conceptual volume and deepened its scope since the mid of the last century, it has started to get integrated in the design processes day by day. By this means, it becomes a significant component of the scientific design processes including research and development activities, instead of being a random aspect of individual design processes [12].

Making innovations using Biomimicry is generally based in two methods: from biology to design and from design to biology. In the first approach, the design limitation is tried to be solved by using a biological phenomenon, whereas in the other method, the design problem is gathered in a specific function, and various organisms and the ecosystem are observed in order to understand the way they solve the said function [13].

Following this information, the categories of biomimicry that can be considered in relation to design was basically divided into the following groups by Volstad and Boks (2012):

- Materials (in material science)

- Mechanics/dynamics (in general engineering and locomotion)

- Structure (in structural engineering and architecture)

- Form (in architecture and art)

It is important to note that the groups above do not refer to the general categorization of areas in which designers specialize, as, for instance, industrial design incorporates much more than can be put into the four 
groups above [2]. Field of interior architecture may also use some of these categories together in this means, as it involves several service areas, such as the design of interiors, furniture design, material selection, repurposing, design of structural elements etc.

Biomimicry based space design criteria, within this scope, need to be approached in a wholistic way and the components of a structured system should not be considered individually. The aim in this approach is not only inspiring from a form in nature, instead, particularly in architectural design, the rules and functions leading and controlling these forms need to be investigated and reflected to the design steps [14].

In the past, interior design profession has not formally incorporated the biomimicry process into its standard practice. The biomimetic approach was offered as an optional method by only a few in the industry. However, biological discoveries are multiplying exponentially, and designers should take advantage of these cutting edge solutions [15]. Understanding how the biological systems effectively get adapted to limited sources and hard conditions seems quite important for biomimicry [13].

This design process extended further through using: mimicking or taking creative inspiration from natural mechanisms such as camouflaging, defense techniques, locomotion, attraction of the opposite, forces of gravity, least energy systems, use of local resources and behavioral patterns as mechanisms of integration and adaptation [11]. These approaches, which are in great respect to the future generations and other forms of living organisms, indicate a nature friendly discipline and a responsible human attitude [12]. Nature is reliable, compatible and sustainable; it uses energy only in its requirement limits, it piles no wastes and is a great recycler. Thus, biomimicry is considered as a pathfinder particularly in designs in engineering sciences. Biological systems are characterized according to their dimensions, sensitivity and strength. These features enable designers to use these principles in developing human made systems. As the things that living organisms do, form the nature's process and characteristics, it becomes a substantial issue for a designer to know these features and to connect them with designs [16].

Within this scope, this study represents an experimental and comparative approach to furniture design inspired by nature. The aim is to bring in a different point of view to furniture design by providing a timeless inspiring agent; and to raise the awareness in terms of biomimicry. The method used in the study, the process and findings are given in the following titles.

\section{METHOD}

This study offers a biology based inspiration for the furniture design activities of interior architecture students. Within this purpose, this study represents a group of senior class students' Furniture Design course outputs -supervised by the authors-, in Hacettepe University (Ankara, Turkey), Department of Interior Architecture and Environmental Design, in this respect.

According to Helms et al. (2009) the biologically inspired design process can be considered in two main processes:

1: Problem-driven biologically inspired design process [4]

Step 1: problem definition

Step 2: reframe the problem

Step 3: biological solution search

Step 4: define the biological solution

Step 5: principle extraction

Step 6: principle application

2: Solution-driven biologically inspired design process [4]

Step 1: biological solution identification

Step 2: define the biological solution

Step 3: principle extraction 
Step 4: reframe the solution

Step 5: problem search

Step 6: problem definition

Step 7: principle application

El-Zeiny (2012) also states that biomimicry, as a design process, typically falls into two categories: Problem- based approach (Top -Down Approach) and Solution-based approach (Bottom-Top Approach) [9].

Within this framework, the scope of the process conducted in this study was planned in accordance with the stages defined by Helms et al. (2009); and the students were organized in two main groups - solutiondriven and problem-driven design processes. The backbone of the whole process is given in Figure 1, in which the substages can also be followed.

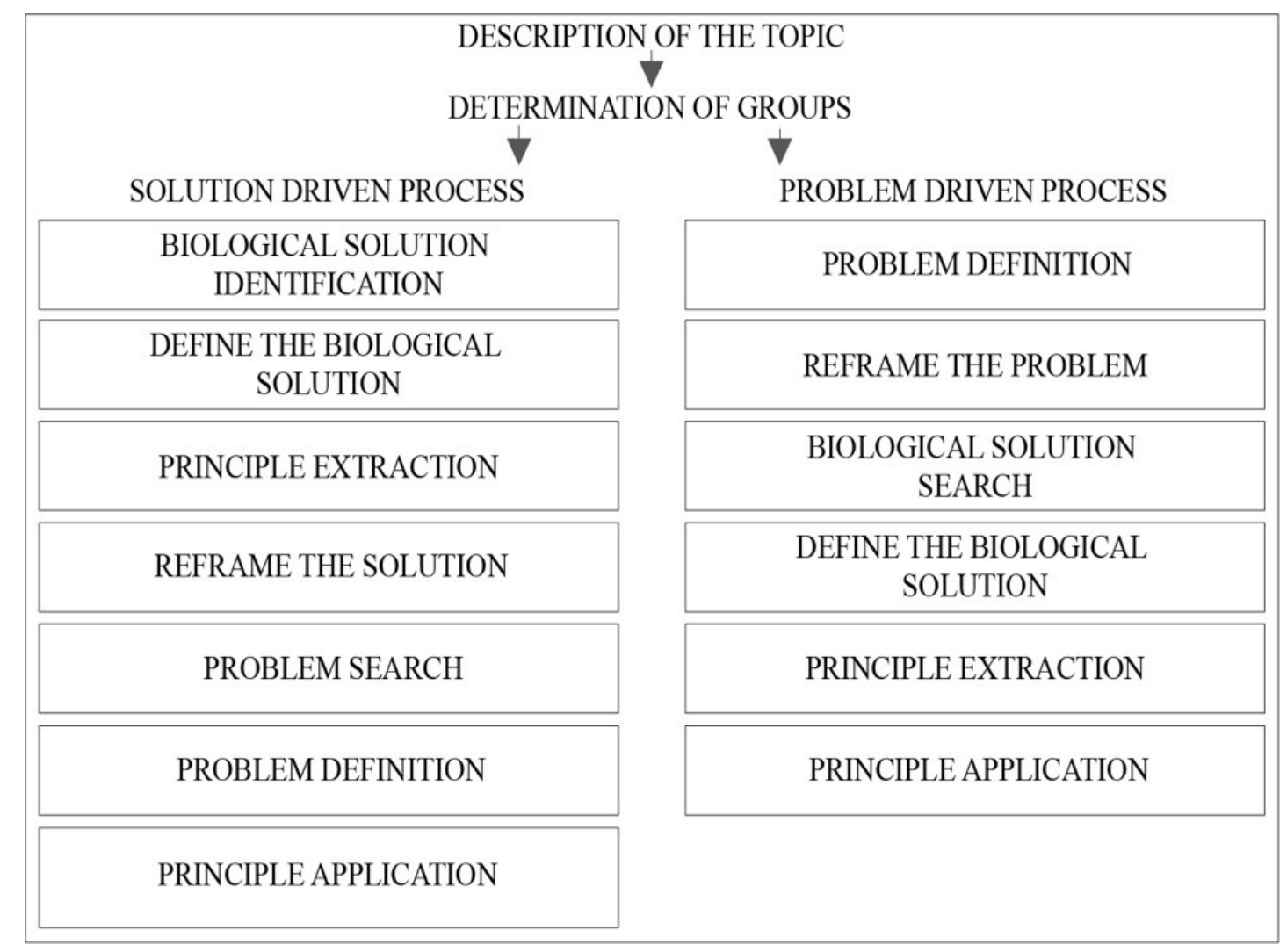

Figure 1. Basic stages and substages of the process.

As it can be seen in Figure 1, firstly the students were informed regarding the scope of the study (description if the topic). In this stage, students were informed about the notion of biomimicry; and they were encouraged to make essential researches on the topic. Secondly, two main groups for working through solution-driven and problem-driven design processes were organized (determination of groups). Figure 1 also shows the substages under these processes. The first group (solution-driven) consisted of 20 students, and the second group (problem-driven) consisted of 18 students. Participants were planned to work individually instead of group works.

Student s worked for 14 weeks and followed all the estimated substages. At the end of the term, 38 designs were put forward in terms of biologically inspired design with 38 different inspiration points. The findings were then assessed and evaluated comparatively, regarding the drivers.

\section{STUDY: BIOLOGICALLY INSPIRED FURNITURE DESIGNS}

As the study involves many substages, it was found useful to present the processes through exemplary works from both groups. Within this scope, solution-driven and problem-driven design processes are to be 
handled respectively under this title. Figure 2, Figure 3 and Figure 4 involve three exemplary works selected among 20 designs put forward in solution-driven group.

\begin{tabular}{|c|c|c|c|c|c|}
\hline $\begin{array}{l}\text { BIOLOGICAL SOLUTION } \\
\text { IDENTIFICATION }\end{array}$ & 1 & $\begin{array}{l}\text { DEFINE THE BIOLOGICAL } \\
\text { SOLUTION }\end{array}$ & 2 & PRINCIPLE EXTRACTION & 3 \\
\hline 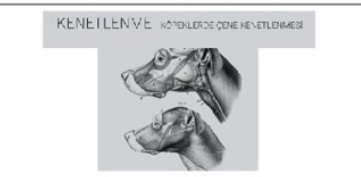 & & $\begin{array}{l}-= \\
y= \\
2\end{array}$ & & $\begin{array}{r}x= \\
3= \\
=-1\end{array}$ & \\
\hline REFRAME THE SOLUTION & 4 & PROBLEM SEARCH & 5 & PROBLEM DEFINITION & 6 \\
\hline 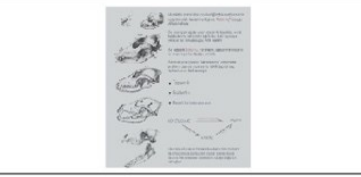 & & 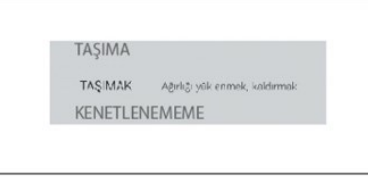 & & $\begin{array}{l}=\frac{11}{5} \\
\equiv=8 \mathrm{c}\end{array}$ & \\
\hline PRINCIPLE APPLICATION & 7 & & & & \\
\hline 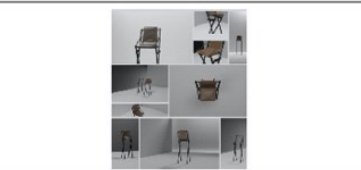 & & & & & \\
\hline
\end{tabular}

Figure 2. First exemplary work (by Cansu Çamur) from the solution-driven group.

As it can be seen in Figure 2, the first substage to be followed for this group was the biological solution identification. In this stage, students were asked to search for a biological solution from nature. The students were free in selecting animals or plants. For instance, in this exemplary study, the lock-in system of the dogs jaw was taken as the inspiration point for the design to be developed. In the second substage, the biological solution was defined broadly; and in the third substage (principle extraction), the working principles of the selected solution were investigated and analyzed in detail. The fourth step was to reframe the solution, in which the main point was figured out. In the fifth step, the problems that may be solved by the selected solution, were specified. For instance, in this example, the outputs of the fifth step were specified as transportation and unlocking. Then, in the fourth step, the problem was defined and the first drafts of the design was put forward. In the last and seventh step, the principle was integrated to the solution, and the design sketches were developed to put forward a new furniture design.

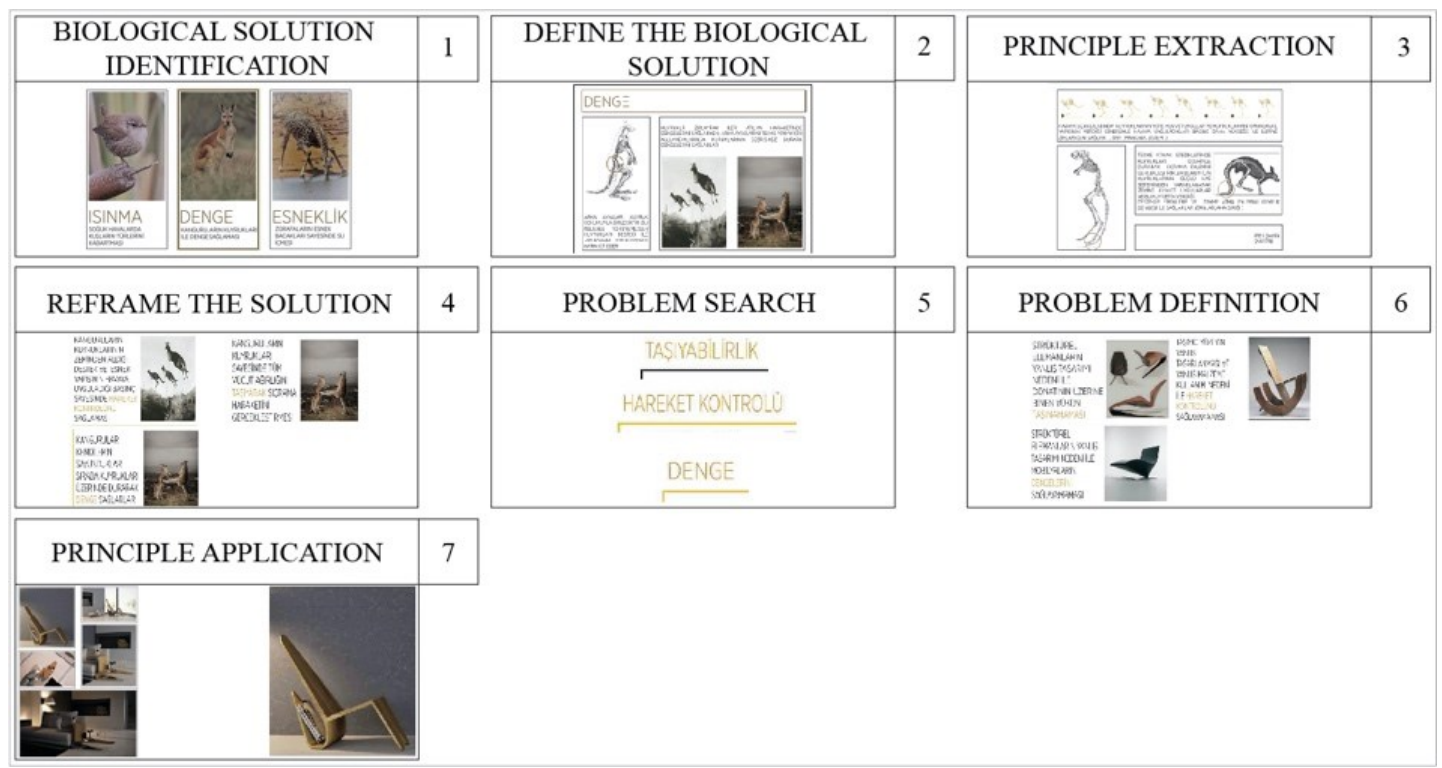

Figure 3. Second exemplary work (by Ipek Şahin) from the solution-driven group.

Figure 3 shows another example, in which the biological solutions of kangaroo was handled. Carrying and balance, were taken into consideration as the main biological solutions. The solution was analyzed in a detailed way, and in the third step, the principle was extracted clearly. After reframing the solution, 
problems were searched and defined as the unbalanced structures of furniture, and the weaknesses in terms of load bearing. In the last and the seventh step, a whole new design can be seen, in which the structural problems are solved by these means; and an open storage unit was provided by getting inspired from the systems initially given in step 1 and 2 .

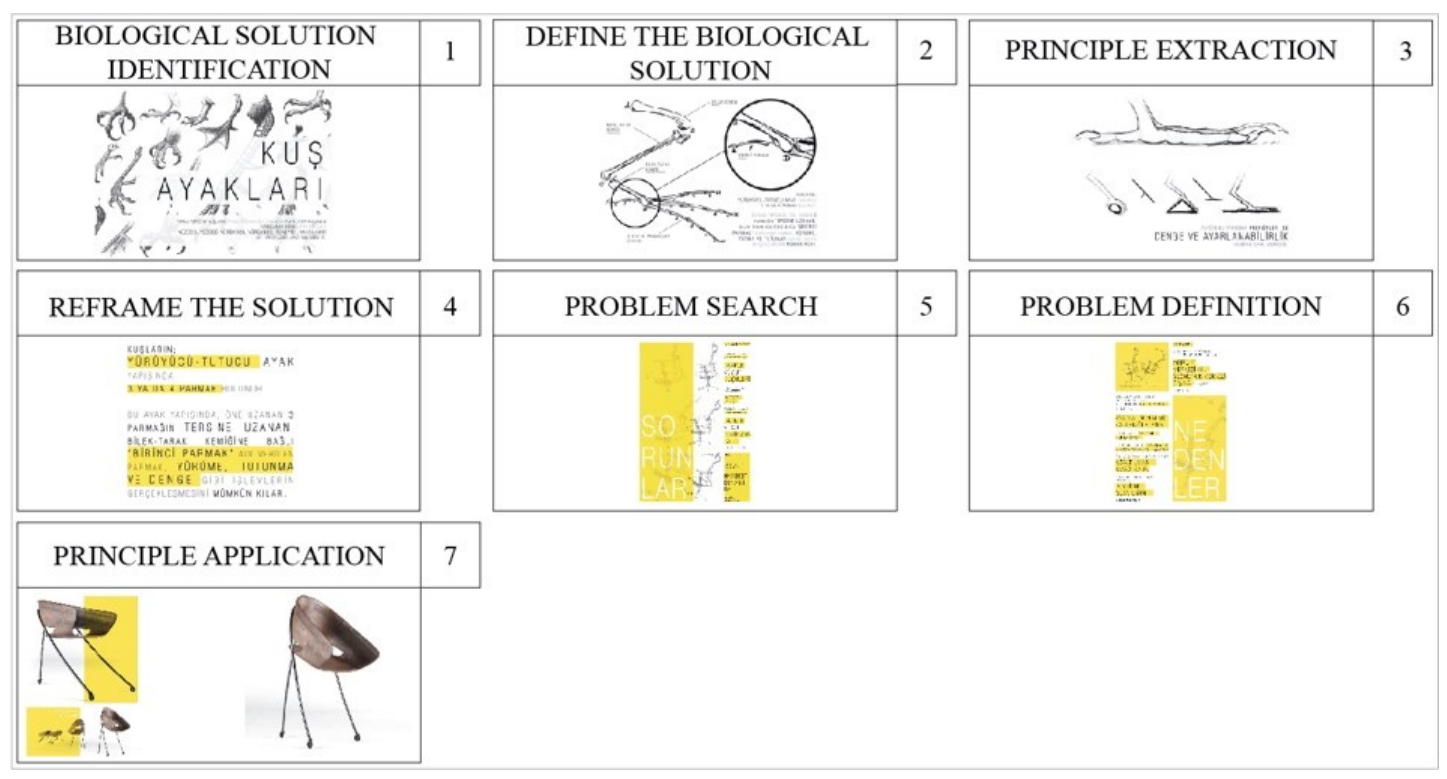

Figure 4. Third exemplary work (by Yusuf Çakar) from the solution-driven group.

Figure 4 shows another exemplary work involving a solution from the birds leg. In step 2, the solution was defined and in step 3 it was extracted as balance and adjustability. In step 4, 5, and 6, the solution was integrated to a problem, as well as done in the previous examples. The last step, involving the principle application, indicates another whole new design, solved through this solution-driven process.

The outputs of the first approach are given in Figure 5. All the designs partaking in the figure were developed according to the solution-driven process; and it can be seen that they offer more of a systematic solution, instead of solely visual innovations. 


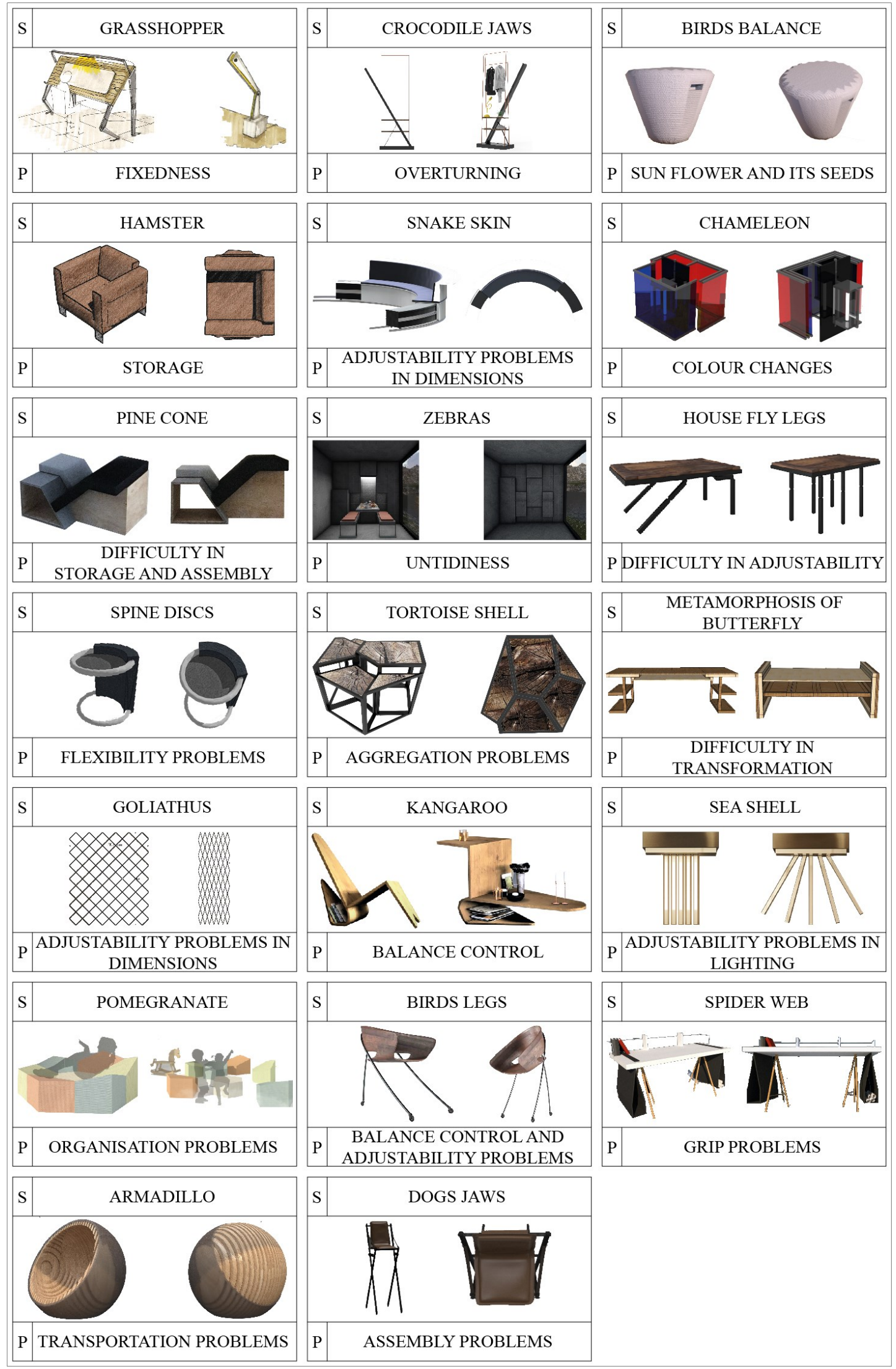

Figure 5. Designs developed in the solution-driven process.

The second approach was the problem-driven design process and 18 students were included in this group. As well as the previously handled process, three exemplary works were selected and presented below in order for explaining the outputs of the substages. 


\begin{tabular}{|c|c|c|c|c|c|}
\hline PROBLEM DEFINITION & 1 & REFRAME THE PROBLEM & 2 & $\begin{array}{l}\text { BIOLOGICAL SOLUTION } \\
\text { SEARCH }\end{array}$ & 3 \\
\hline \begin{tabular}{l||l||} 
decoloma \\
|strüktưr \\
yer deḡistirememe
\end{tabular} & & 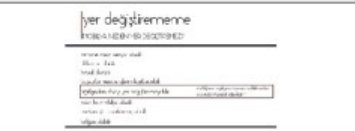 & & $=\frac{A 4}{a t}$ & \\
\hline $\begin{array}{c}\text { DEFINE THE BIOLOGICAL } \\
\text { SOLUTION }\end{array}$ & 4 & PRINCIPLE EXTRACTION & 5 & PRINCIPLE APPLICATION & 6 \\
\hline 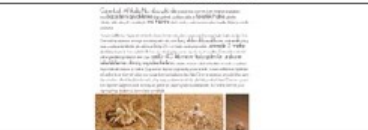 & & 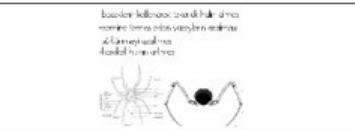 & & 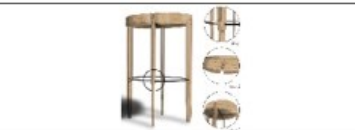 & \\
\hline
\end{tabular}

Figure 6. First exemplary work (by Huriye Ylldiz) from the problem-driven group.

Figure 6 indicates the 6 step process, as this approach involves a 6 step progress different from the solutiondriven design process. Besides, it can be seen that in this process, the steps are reversely sequenced contrary to the first approach. In the first step, the problem was found and defined by the student. For instance, in this example, the problems were determined as storage, structural strength and immobility/fixedness, and reframed in step 2. For this problem, nature was observed and analyzed in step 3 (biological solution search). In step 4, the biological solutions were defined and explained in detail; and in step 5, it was extracted as the spider legs system. In the last step (principle application), a new design, an adjustable stool -involving the biologically inspired solutions such as adjustable legs and with fine and strong structurewas developed.

\begin{tabular}{|c|c|c|c|c|c|}
\hline PROBLEM DEFINITION & 1 & REFRAME THE PROBLEM & 2 & $\begin{array}{c}\text { BIOLOGICAL SOLUTION } \\
\text { SEARCH }\end{array}$ & 3 \\
\hline 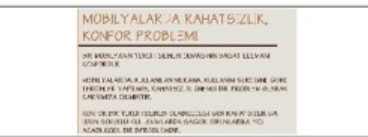 & & 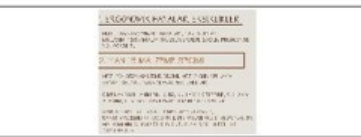 & & 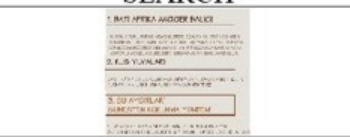 & \\
\hline $\begin{array}{l}\text { DEFINE THE BIOLOGICAL } \\
\text { SOLUTION }\end{array}$ & 4 & PRINCIPLE EXTRACTION & 5 & PRINCIPLE APPLICATION & 6 \\
\hline 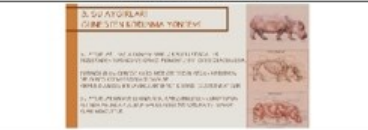 & & $=1$ & & 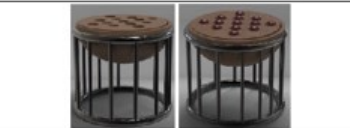 & \\
\hline
\end{tabular}

Figure 7. Second exemplary work (by Kübra Keleş) from the problem-driven group.

Figure 7 shows another exemplary work from the problem-driven group, in which the problem was defined as discomfort. The problem was reframed in step 2 as wrong material selection. In step 3, biological solutions for this problem were searched, and the solution was found in hippopotamus skin. In step 4, the solution system was specified as the sun protection mechanism existing in the skin of hippopotamus. Following a deep research and observation process, the principle was extracted into the skin's micro structure. The skin emits a pigmented liquid to protect the animal from the UV rays of sun. This system indicates an action-reaction mechanism, which gives inspiration to the designer. In step 6, a new design was put forward, which has a changeable surface, in terms of softness, according to the weight it meets.

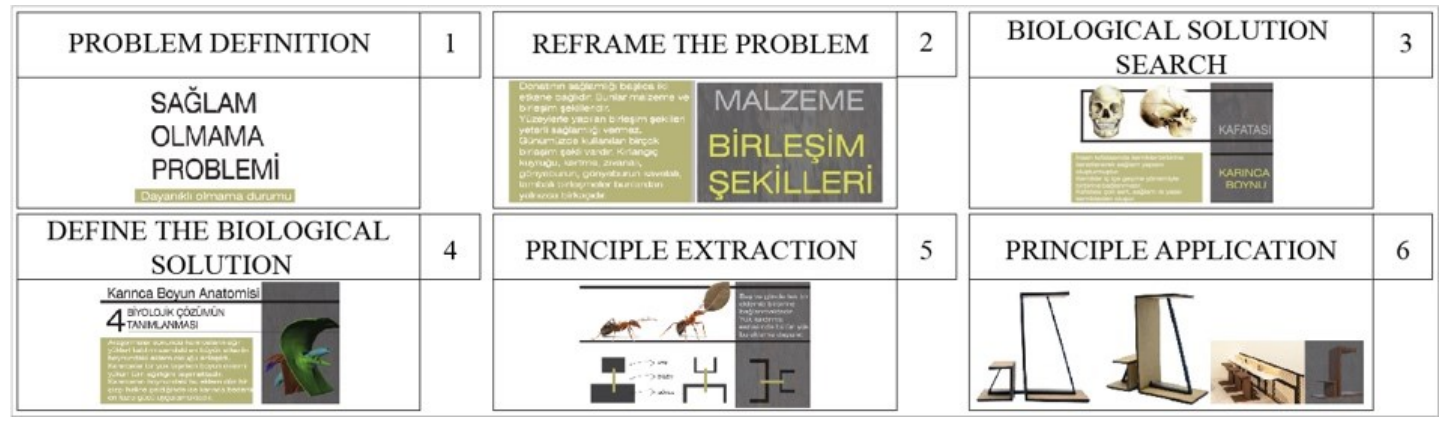

Figure 8. Third exemplary work (by Nur Yağmur Oğullar) from the problem-driven group.

Figure 8 shows a process driven by problem of being unfirm. The problem was reframed into constructional systems in step 2. In step 3, the solution was searched and defined as the ants' neck anatomy, in step 4 . The principle was analyzed and extracted in step 5 , and the neck anatomy was adapted to the construction system 
as a bearing element. In step 6, the principle was applied in a new design as a table/stool construction system.

All the designs put forward by this means (problem-driven process) were represented in Figure 9.
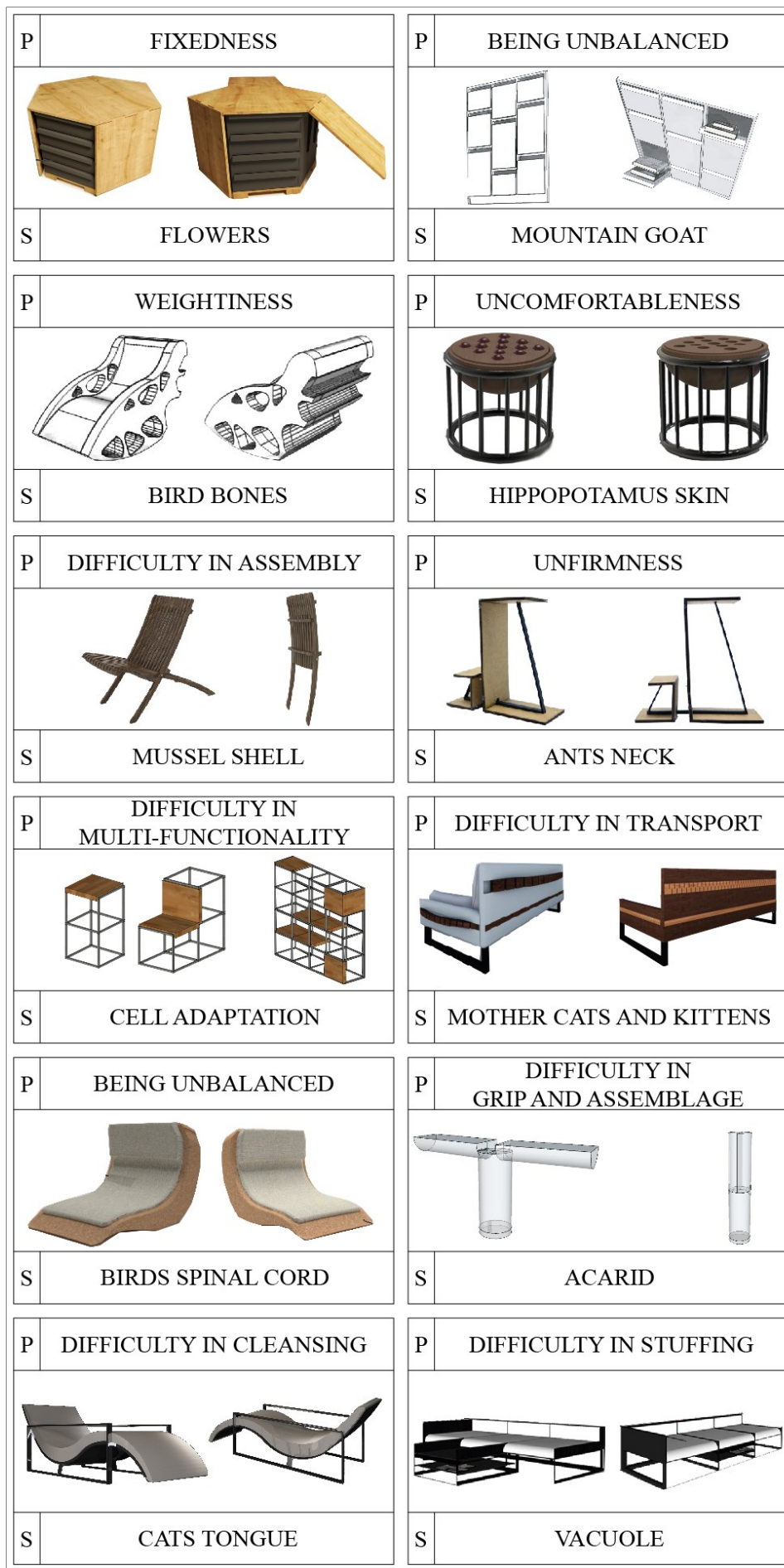
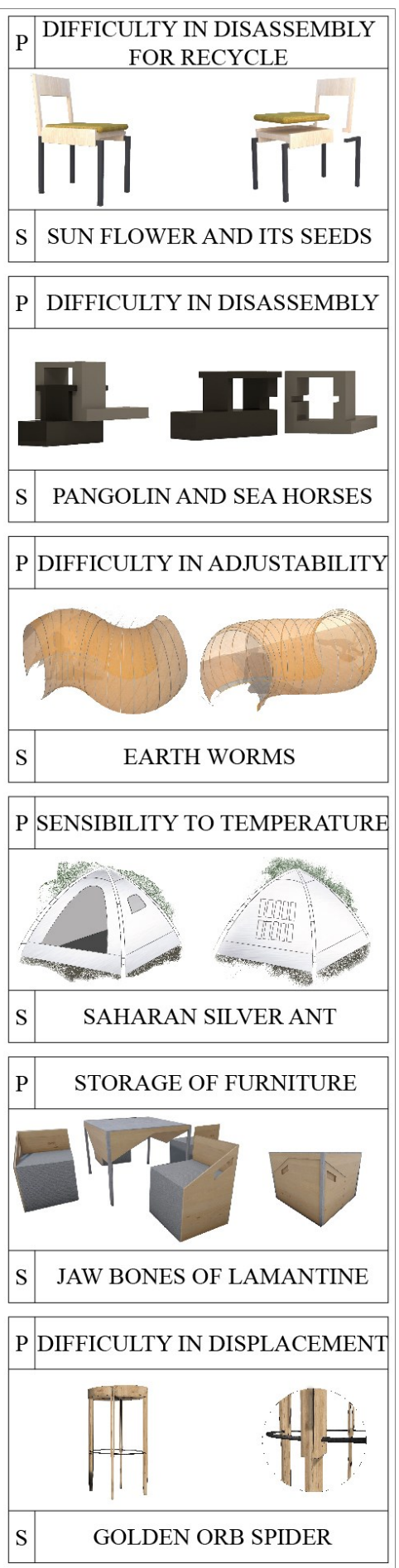

S GOLDEN ORB SPIDER

Figure 9. Designs developed in the problem-driven process.

In either Figure 5 or Figure 9, the biological inspiration points and solutions were written together above the designs, in order the impacts to be observed.

\section{CONCLUSIONS}


When the processes are analyzed, it was observed that searching and finding a solution from nature was found easier than defining a problem as an initial point. In other words, giving a start to the solution-driven process was found to be a more flowing act.

In the solution-driven process, nature was taken either as a formal or a functional inspiration point; whereas in the problem-driven process, the functional aspects were taken into account in the first place.

Functional integration can help to identify hierarchical connections and the synergy between technology, materials, structure and form [11].

However, the integration of chemical or micro scale solutions -such as shiny bacteria- to the design process were found to be a more complicated act in both processes; and it was observed that students might have desisted from using such aspects.

Besides, in the solution-driven process, students considered the two sequential steps together; step 3principle extraction and step 4-reframe the solution. While, in problem-driven process, it can be said that steps were more definite.

In both processes, it would not be wrong to say that the last steps-principle application involved a particular process, compared to the other steps in each process. Research and analysis based actions, seen in several steps, gave place to sketching, design development and the usage of professional notions in the final steps.

Thus, it can be said that in both processes, the first steps involved the preparation stages regarding the design inputs, whereas in final steps a transform of information regarding the design output can be observed. It can also be said that these two linear processes may relate to two essential methods; inductive method and deductive method. In problem-driven process, the originating point is defined as a problem and in order to achieve the goal, the designer follows a progressive and accretionary task, just as in the inductive method. However in the solution-driven process, the final point is taken as a starting point, in other words a reverse action is made. Thus, a narrowing and customizing procedure comes forward similar to the deductive method.

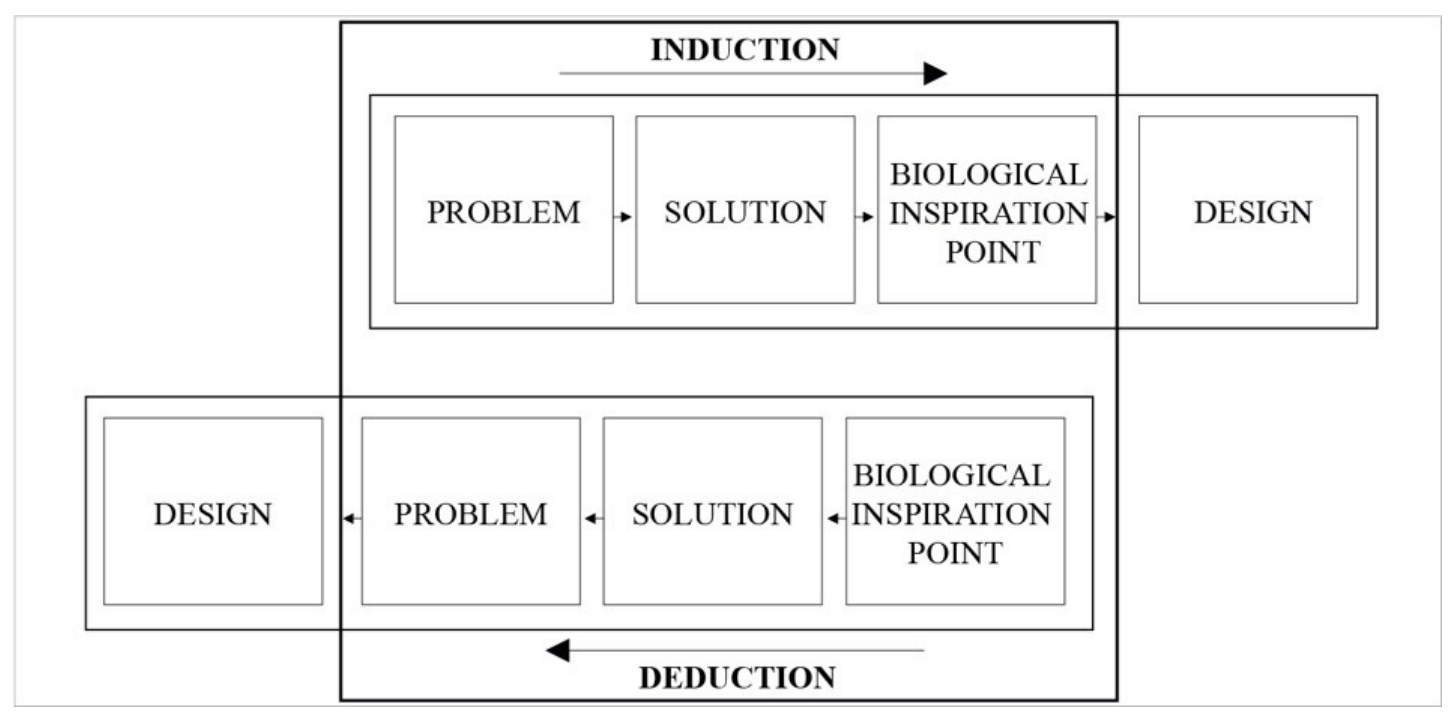

Figure 10. Biologically inspired design activity.

In conclusion, both processes provided high potency conceptual and final product designs. As the aim of the study was not to reveal the more accomplished method, no such determination shall be made. Hence, the different experiences gained in both processes were tried to be introduced; and an alternative design inspiration system was suggested for further studies since the nature is considered as a timeless inspiration source for the whole design field.

\section{ACKNOWLEDGEMENTS}

The authors would like to extend their sincere thanks to Anıl Tunçez, Atiye Yağmur Özcan, Ayşe Hande Çakır, Ayşe Meryem Gürel, Begüm Zülal Çelik, Beren Alp, Betül Gökdemir, Bilge Akalın, Billur Zeynep 
Şengül, Buse Kul, Büşra Çobanoğlu, Büşra İnal, Cansu Çamur, Cemre Kaplan, Ebrar Kuruçay, Ecem Karagedikli, Esin Keçeli, Esra Taban, Gülsu Merve Öcal, Hamed Ahmadzadeh, Hatice Tül Kübra Çerez, Hilal Özcan, Huriye Yıldız, İlknur Soykan, İpek Şahin, İrem Gizem Öztürk, Kardelen Berfin Acar, Kübra Keleş, Nevzat Erkmen Dönmez, Nur Yağmur Oğullar, Özge Külünk, Rana Karaömer, Saynur Turhan, Serdar Çoban, Sümeyye Teke, Şeymanur Tunay, Yasemin Mülazım, Yusuf Çakar.

\section{REFERENCES}

[1] Maglic, M. J. (2021). Biomimicry: Using Nature as A Model for Design. Master's Thesis. Massachusetts: Architecture, University of Massachusetts Amherst.

[2] Volstad, N. and Boks, C. (2012). On the use of Biomimicry as a Useful Tool for the Industrial Designer. Sustainable Development, 20(3), 189-199. https://doi.org/10.1002/sd.1535

[3] Kennedy, E. B. (2017). Biomimicry: Design by Analogy to Biology. Research-Technology Management, 60(6), 51-56. https://doi.org/10.1080/08956308.2017.1373052

[4] Helms, M., Vattam, S. and Goel, A. (2009). Biologically Inspired Design: Process and Products. Design Studies, 30, 606-622.

[5] Chakrabarti, A. and Shu, L.H. (2010). Biologically inspired design. Edam Artificial Intelligence for Engineering Design, Analysis and Manufacturing - AIEDAM, 24(4), 453-454. https://doi.org/10.1017/S0890060410000326

[6] İnner, S. (2019). Biyomimikri ve Parametrik Tasarım İlişkisinin Mimari Alanında Kullanımı ve Gelişimi. Tasarım Enformatiği, 1 (1), 15-29.

[7] Yazıcı, A. M. and Kınay, M. (2021). Biyomimikri, Uzay Araştırmaları İçin Robotiklere Nasıl İlham Veriyor?. Türk Hava Kurumu Üniversitesi Havacılık ve Uzay Çalışmaları Dergisi, 1 (2), 64-77.

[8] de Pauw, I. C., Karana, E., Kandachar, P. and Poppelaars, F. (2014). Comparing Biomimicry and Cradle to Cradle with Ecodesign: a case study of student design projects. Journal of Cleaner Production, 78, 174-183. https://doi.org/10.1016/j.jclepro.2014.04.077

[9]El-Zeiny, R. M. A. (2012). Biomimicry as a Problem Solving Methodology in Interior Architecture. ASEAN Conference on Environment-Behaviour Studies, Bangkok, Thailand. $502-512$.

[10] Benyus, J. M.(1997). Biomimicry: Innovation Inspired by Nature. Perennial: An Imprint of Harper Collins Publishers.

[11] Gamage, A. and Hyde, R. (2012). A model based on Biomimicry to enhance ecologically sustainable design. Architectural Science Review, 55, 224-235. https://doi.org/10.1080/00038628.2012.709406

[12] Çelikel, S.B. ve Uçar, S. (2020). Biyomimikri: Doğayla Uyumlu Yeni Bir Tasarım Modeli, Humanities Sciences (NWSAHS), 15 (2), 51-60.

[13] Eryılmaz, H. (2015). Biyomimikri ve Ergonomi: Tasarımda Doğadan Yenilikçi İlham. Süleyman Demirel University Journal of Engineering Sciences and Design, 3 (3), 469 - 474.

[14] Keskin, S. N. and Özen Yavuz, A. (2019). Biyomimikri Yöntemiyle Tasarlanmış Bir Yaşam Alanı: Salyangoz Barınağı. ISAS $20193^{\text {rd }}$ International Symposium on Innovative Approaches in Scientific Studies, SETSCI Conference Proceedings, 4 (3), 88-93.

[15] Rossin, K. J. (2010). Biomimicry: nature's design process versus the designer's process. WIT Transactions on Ecology and the Environment, 138, 1743-3541. Doi: 10.2495/DN100501

[16] Karabetça, A. R. (2018). Biyomimikri Destekli Tasarım Ölçütleri İle Yenilikçi Mekanlar Yaratılması. The Turkish Online Journal of Design, Art and Communication - TOJDAC, 8 (1), 104-111. 